\title{
MIELINIZAÇÃO, DESMIELINIZAÇÃO E REMIELINIZAÇÃO NO SISTEMA NERVOSO CENTRAL
}

\author{
DOMINGUITA LUHERS GRACA *
}

\begin{abstract}
RESUMO - As bainhas de mielina que cnvolvem axônios nu SNC são fejtas c mantidas por oligodendrócitos. Estas células gliais formam um número variável de segmentos de mielina (internódulos): entre 1 e 200, de modo que quando uma célula é lesada junto com ela podem ser destruídos numerosos interródulos, constituindo um processo desmielinizante. Como conseqüência da destruiçāo da célula-bainha e internódulos relacionados há uma resposta celular rápida e abundante. Está resposta é leita por fagócitos residentes (microglia) e hematógenos. Ambas as células fagocitam os detritos celulares e de mielina, deixando os axônios desmielinizados. Estes axônios podem permanecer desprovidos de suas bainhas e aglutinados, podem ser scparados por processos de astrócitos ou podem ser remielinizados. A ocorrência do processo de remielinização depende da intensidade e tempo de exposição ao agente desmielinizante. A remielinização, com total restabelecimento da conduçāo, pode ser realizada por oligodendrócito ou por célula de Schwann que invade o SNC sempre que os astrócitos são destruídos.
\end{abstract}

\section{Myelinution, demyelination and remyelination in the central nervous system.}

SUMMARY - The myelin sheaths that surround axons in the CNS are made aind maintained by oligodendrocytes. These glial cells can form variable numbers of myelin segments (internodules): from 1 to 200 so that when one oligodendrocyte is destroyed with preservation of the axon, many internodules can be lost, constituting a demyelinating process. As a consequence of the destruction of myelin and sheath cells a rapid and abundant cell response takes place. The response is made up by resident (microglia) and haematogenous phagocytes which phagocytose myelin and cellular debris leaving the axons demyelinated. Demyelinated axons may either stay demyelinated and clumped together or they may be separated by astrocytic processes, yet they can be remyelinated. The occurrence of remyelination depends upon the intensity and time of exposition to the demyelinating agent. Remyelination in the CNS with complete restoration of conduction may be made by oligodendrocytes or Schwann cells which invade the CNS when astrocytes are destroyed.

A bainha de mielina, estrutura lipoproteica depositada ao redor de axônios selecionados em internódulos, interrompidos periodicamente pelos nódulos de Ranvier (Fig. 1), permite a condução saltatória, rápida e eficaz no sistema nervoso dos vertebrados. As células que constróem a mielina são o oligodendrócito no sistema nervoso central (SNC) e a célula de Schwann no sistema nervoso periférico (SNP). Um oligodendrócito mieliniza um ou vários axônios, até 20043 , enquanto a célula de Schwann forma sempre um único internódulo de mielina. Assim, conclui-se que sempre é mais grave uma lesão que atinja um oligodendrócito que a causada pela destruição de uma célula de Schwann 27,39 .

Departamento de Patologia da Universidade Federal de Santa Maria: * Professor Adjunto, DMV, PhD.

Departamento de Patologia, Universidade Federal de Santa Maria - 97110 Santa Maria RS Brasil. 
Processo de mielinização - A mielinização envolve estreitas e complexas interações entre os axônios e suas células-bainha. A interação começa com um sinal do axônio que age no recrutamento de populações celulares potencialmente mielinizantes, na sua diferenciação e proliferação e na iniciação da síntese e manutenção das moléculas especificas da mielina 1,8,33.

Além dos fatores axônio e célula-bainha, existe a exigência de um terceiro fator para a estabilização das relaçōes entre ambos; no SNP esse terceiro fator é consistido de fibras colágenas preformadas 10,11. Foi sugerido que no SNC tal função estabilizadora seja realizada pelo elemento estrutural mais importante do tecido, o astrócito fibroso tipo $25,11,35$. Hoje está comprovada a especialização da linhagem oligodendrócito-astrócito tipo 2 para mielinização no SNC 14.

Formação da bainha de mielina - O processo de mielinização se inicia quando uma projeção da célula-bainha envolve o axônio e forma espiral frouxa ao seu redor. Com o tempo as camadas formadas se compactam pela expulsão do citoplasma e formam estrutura lamelar com bandas eletrodensas espessas - derivadas da aposição das fases citoplasmáticas das membranas - e menos eletrodensas - derivadas da aposição das fases externas das membranas. Ambas as bandas recebem a denominação de linha densa principal (LDP) e linha intraperiódica (LI) respectivamente $23,24,36,39$ (Fig. 1).

Desmielinização - No processo de desmielinização há dano segmentar à mielina sem lesão axonal $6,7,27,45$, sendo assim distinguido da degeneração walleriana, processo no qual ocorre degradação da mielina como consequência da degeneração axonal. A desmielinização é observada em muitas doenças espontâneas do homem e de animais. O processo pode ocorrer como principal componente da doença tal como na esclerose múltipla no homem 2 , e cinomose nos cães 42,48 , ou como alteração secundária a reações inflamatórias ou imunomediadas 7,44,47. Com a finalidade de esclarecer esses processos, têm sido desenvolvidos modelos experimentais de desmielinização pelo uso de técnicas tais como: inoculação de vírus que lisam oligodentrócitos, como por exemplo o da hepatite do camundongo (JHM) 17,37; indução de reações imunológicas contra células que expressam antigenos virais 25; indução de reaçōes imunológicas in vivo pela inoculação intradérmica de cérebro emulsionado 27,29 e in vitro pela adição de soro mielinotóxico a culturas de células gliais 26,40 ; injeção local ou sistêmica de agentes mielinotóxicos 8,18-20; pelo uso de pressão sobre a mielina 12,13,15,16,22. Após a exposição da substância branca a agentes lesivos, a mielina sofre degradação associada a infiltração macrofágica na área. As bainhas podem sofrer alteraçōes antes de ser fagocitadas, tais como vesiculação e formação de favos 46, micropinocitose vermiforme 38,41 e desnudamento, associado a profusa infiltração macrofágica 28 . Os axônios desmielinizados podem ser remielinizados (veja a seguir) ou permanecer desprovidos de suas bainhas, separados por processos de astrócitos (Fig. 2). Nos casos em que os astrócitos estão ausentes da área da lesão, os axônios se aglutinam 20.

Remielinização - O termo remielinização significa reconstrução das bainhas perdidas. Como na esclerose múltipla, a doença desmielinizante mais importante do homem, há falha na remielinização, por muito tempo foi pensado que este processo não tinha lugar no SNC. A remielinização no SNC foi descrita pela primeira vez por Bunge et al 9 após induzir desmielinização no gato por barbotagem do líquicéfalo-raquidiano. Embora o processo de remielinizaçăo seja possivel, ele depende de fatores tais como a intensidade e o tempo de exposição ao agente desmielinizante, como ficou provado no modelo do cuprizone $3,31,32$. A remielinização no SNC pode ser efetivada pelo oligodendrócito ou pela célula de Schwann desde que os astrócitos também tenham desaparecido da área da lesão 18. Os internódulos reconstruídos no SNC são reconhecidos principalmente pela espessura da bainha de mielina, que é mais fina que o normal para o diâmetro do axônio 4,21,34. A distinção entre um internódulo reconstruído por um oligodendrócito ou por uma célula de Schwann se faz pela periodicidade das lamelas de mielina - que é maior no SNP — e pela presença de membrana basal ao redor da célula de Schwann. Quando o processo de remielinização é feito pelas duas células-bainha, os oligodendrócitos se localizam adjacentes à substância branca normal enquanto as células de Schwann se distribuem nas áreas perivasculares e subpiais (Fig 3). Em conclusão, sabe-se hoje que a substância branca do SNC tem capacidade de reparação, a partir de oligodendrócitos e/ou células de Schwann que invadem o SNC sempre que os astrócitos são destruidos. Este fato não representa desvantagem para o tecido desde que a condução se restabelece apropriadamente, seja através de uma bainha central ou de uma periférica. 

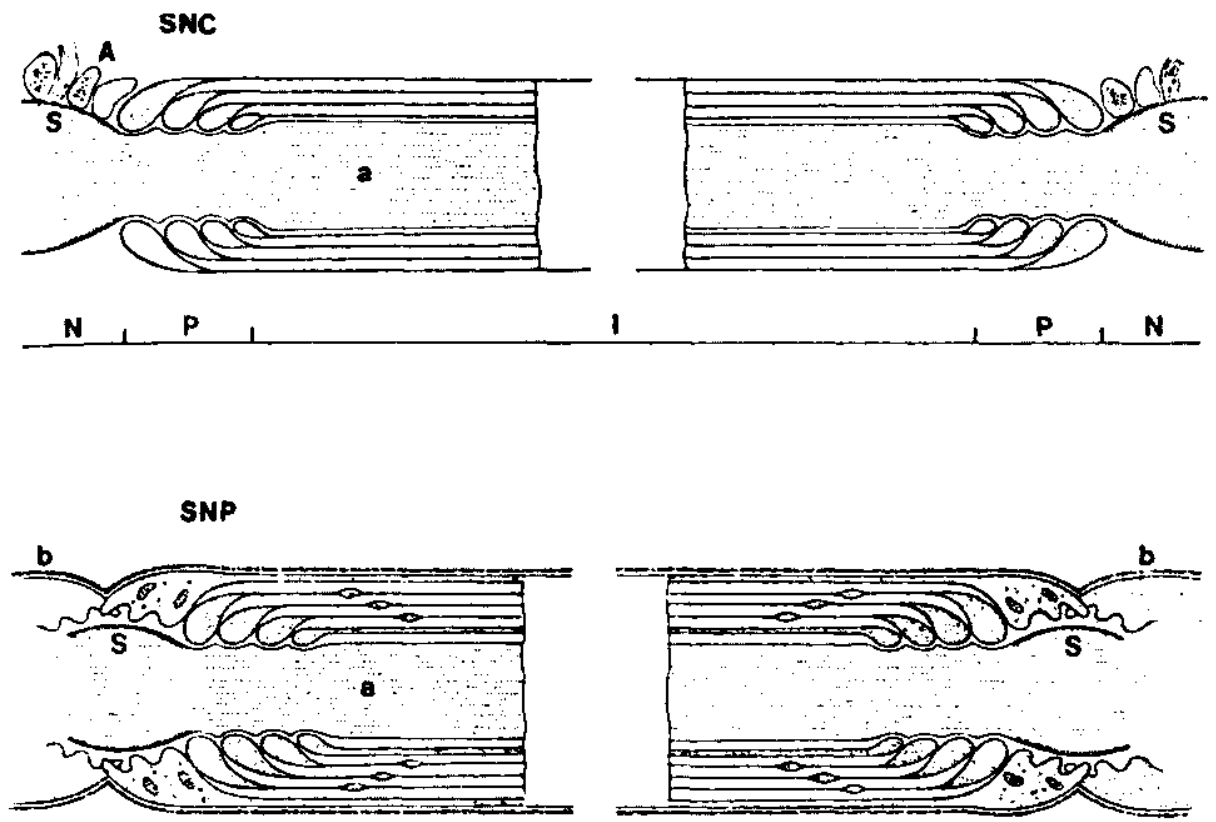

$\mathbf{N}, \mathbf{P}, \quad \mathbf{I}$

I L $\quad$ P , N N N

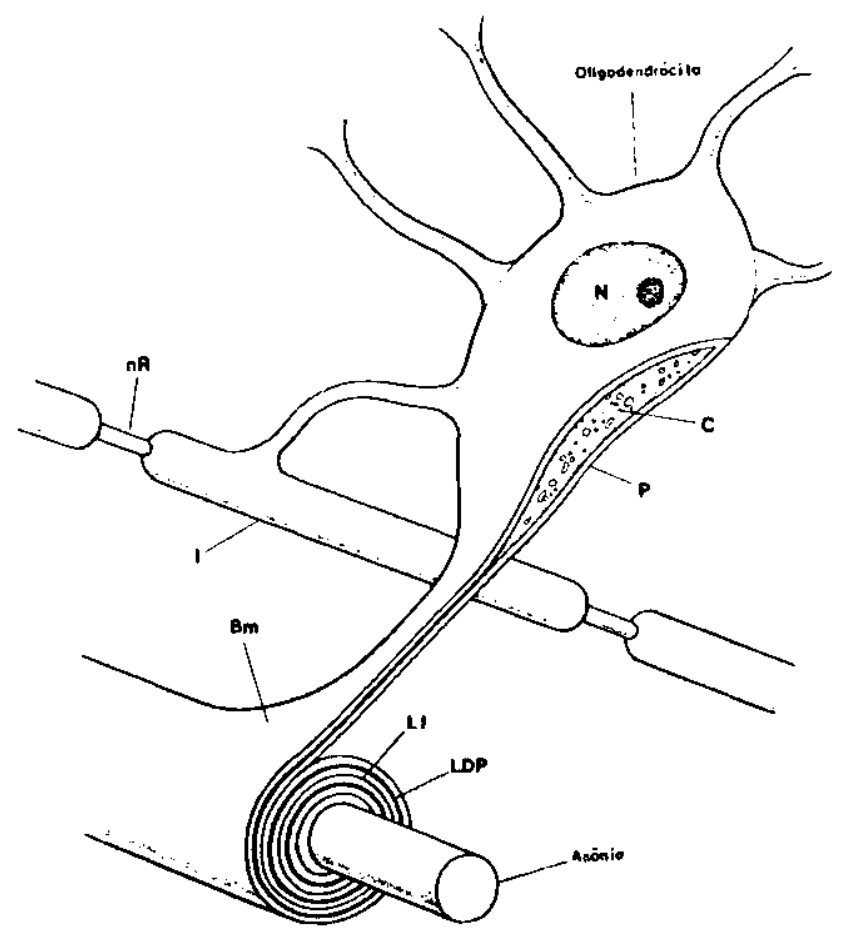

Fig. 1 - No alto, internodulos de mielina nos sistemas nervosos central (SNC) $e$ periférico (SNP): $a$, axónio; $S$, densidades subaxolemais; $A$, processas de astrócitos; $N$, nódulo de Ranvier; $P$, região paranodal; 1 , internodulo; $b$, membrana basal da celula de $\$ c h w a n n$. Em baixo, mielinização pelo oligodendrocito no SNC: $N$, núcleo; $C$, citoplasma; $P$, membrana citoplasmatica; $n R$, nodulo de Ranvier; $B m$, bainha de mielina; $I$, internoduto; $L I$, linha intraperiodica; LDP, linha densa principal (30). 


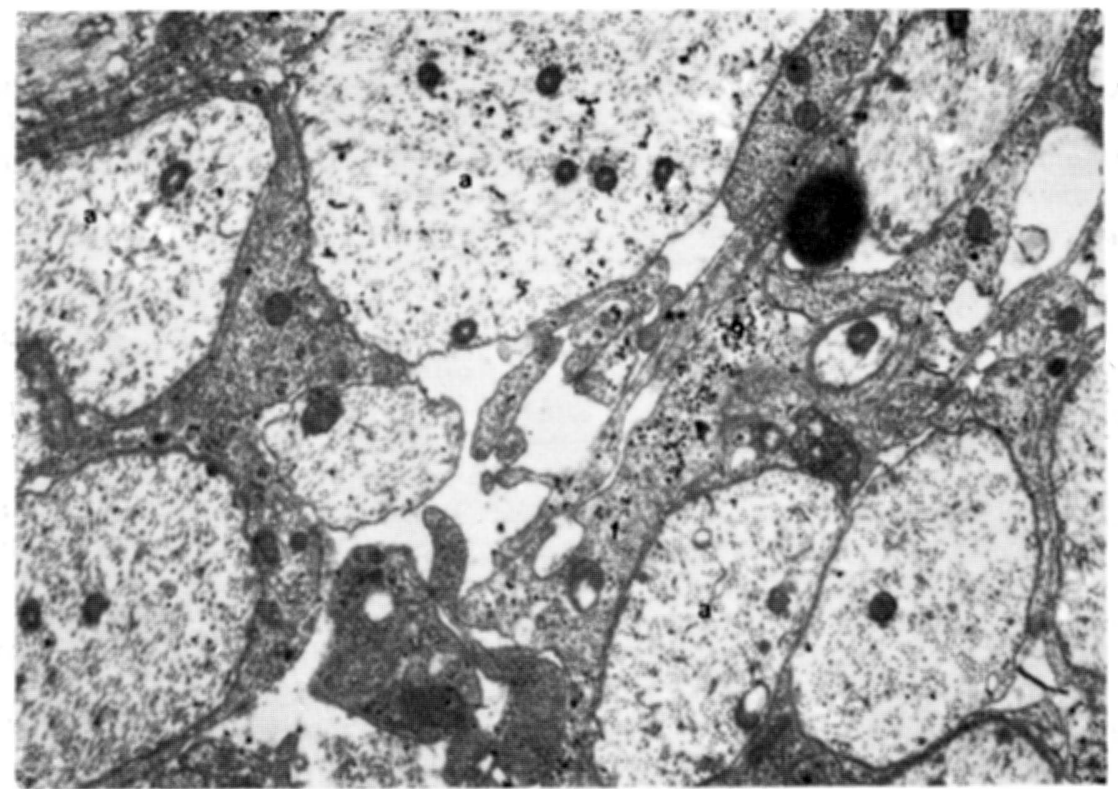

Fig. 2 - Substancia branca da medula espinhal de rato 7 dias após injeção de brometo de etídio: axônios desmielinizados(a) são separados por processos de astrócitos ricos em filamentos gliais(f) e grânulos de glicogênio(g) (×16000).

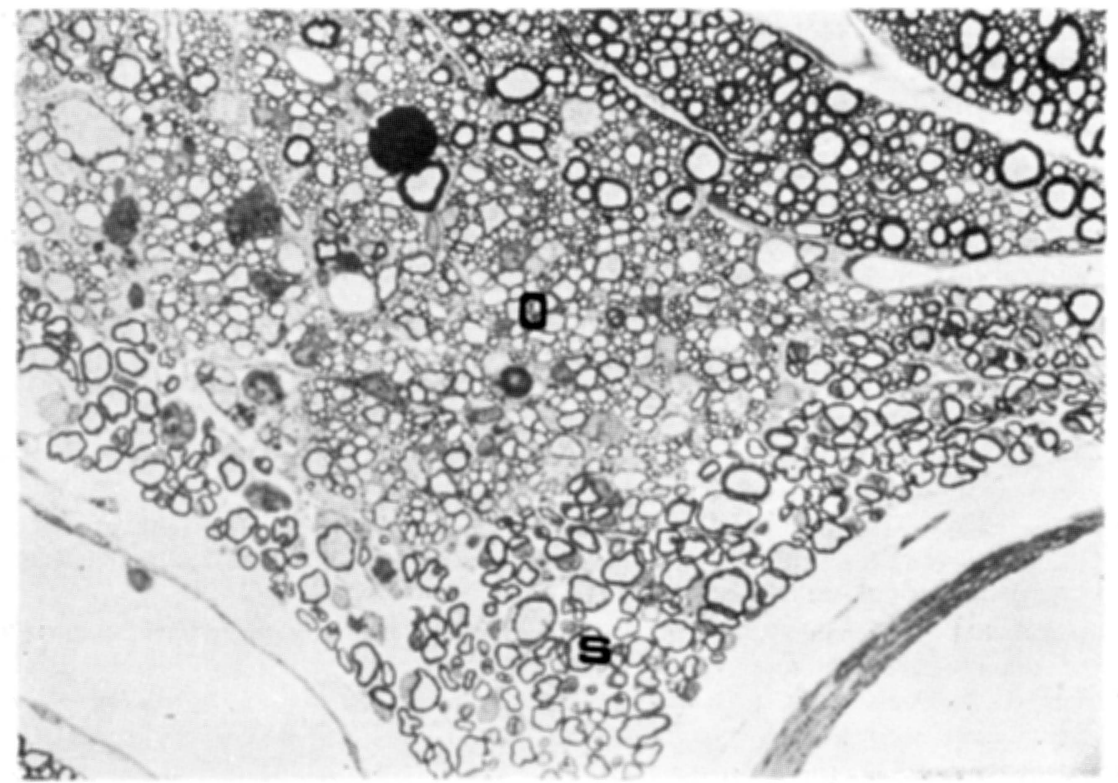

Fig. 3 - Coluna ventral da medula espinhal de rato 120 dias após injeção local de brometo de etidio: a área remielinizada por oligodendrócitos(O) é extensa $e$ adjacente à substancia branca normal; a área remielinizada por células de Schwann(S) ocupa estreita faixa subpial (×300). 


\section{REFERENCLAS}

1. Aguayo AJ, Bray GM - Developmental disorders of myelination in mouse mutants. In Sears TA (ed): Neuronal-Glial Cell Interrelationships. Springer, Berlin, 1982, pg 57.

2. Allen IV - The pathology of multiple sclerosis: fact, fiction and hypothesis. Neuropathol Appl Neurobiol $7: 169,1981$.

3. Blakemore WF - Remyelination of the superior cerebellar peduncle in the mouse following demyelination induced by feeding cuprizone. J Neurol Sci 20:73, 1973.

4. Blakemore WF - Pattern of demyelination in the CNS. Nature 249:577, 1974.

5. Blakemore WF - Observations on remyelination in the rabbit spinal cord following demyelination induced by lysolecithin. Neuropathol Appl Neurobiol 4:47, 1978.

6. Blakemore WF - Myelination, demyelination and remyelination in the central nervous system. In Philipson AF, Hall LW, Pritchard WR (eds): Scientific Foundations of Veterinary Medicine. Heineman, London, 1980, pg 61.

7. Blakemore WF - Myelination, demyelination and remyelination in the CNS. In Cavanagh JB. Smith WT (eds): Recent Advances in Neuropathology. Churchill Livingstone, Edinburgh, 1982, pgr 53 .

8. Blakemore WF, Crang AJ, Evans RJ - The effect of chemical injury on oligodendrocytes. In Mims CA, Cuzner ML, Kelly RE (eds): Viruses and Demyelinating Diseases. Academic Press, London, 1983, pg 167.

9. Bunge MB, Bunge RP, Ris $\mathrm{H}$ - Ultrastructural study of remyelination in an experimental lesion in adult cat spinal cord. $J$ Biophys Biochem Cytol 10:67, 1961.

10. Bunge RP, Bunge MB - Evidence that contact with connective tissue matrix is reauired for normal interaction between Schwann cells and nerve fibres. $J$ Cell Biol 78:943, 1978.

11. Bunge RP, Bunge MB, Cochran $\mathbf{M}$ - Some factors influencing the proliferation and differentiation of myelin-forming cells. Neurology 28:59, 1978.

12. Clifford-Jones RE, Landon DN, McDonald WI - Remyelination during optic nerve compression. $J$ Neurol Sci $46: 239,1980$.

13. Clifford-Jones RE, McDonald WI, Landon DN - Chronic optic nerve compression: an experimental study. Brain 108:241, 1985.

14. French-Constant $\mathrm{C}$, Raff $\mathrm{MC}$ - The oligodendrocyte-type-2 astrocyte cell lineage is specialized for myelination. Nature 323:335, 1986.

15. Fish CJ - Partial demyelination in the spinal cord. Tese. University of Cambridge, 1984.

16. Fish CJ, Blakemore WF - A model of chronic spinal cord compression in the cat. Neuropathol Appl Neurobiol 9:109, 1983.

17. Fleury, HJA, Sheppard RD, Bornstein MB, Raine CS - Further ultrastructural observations of virus morphogenesis and myelin pathology in JHM virus encephalomyelitis. Neuropathol AppI Neurobiol 6:165, 1980.

18. Graca DL - Investigation into ethidium bromide induced demyelination in the central nervous system. Tese. University of Cambridge, 1986.

19. Graca DL, Blakemore WF - The formation of intracytoplasmic «scrolls» followin local injections of ethidium bromide. Neuropathol Appl Neurobiol 11:'73, 1985.

20. Graca DL, Blakemore WF - Delayed remyelination in rat spinal cord following ethidium bromide injection. Neuropathol Appl Neurobiol 12:593, 1986.

21. Harrison BM - Remyelination in the central nervous system. In Hallpike JF, Adams CWM, Tourtellotte WW (eds): Multiple Sclerosis: Pathology, Diagnosis and Treatment. Chapman, London, 1983, pg 461.

22. Harrison BM, McDonald WI - Remyelination after transient experimental compression of the spinal cord. Ann Neurol 1:542, 1977.

23. Hirano A, Dembitzer HM - A structural analysis of the myelin sheath in the central nervous system. $\mathrm{J}$ Cell Biol $34: 555,1967$.

24. Hirano A, Dembitzer HM - Morphology of normal central myelinated axons. In Waxman SG (ed): Physiology and Pathobiology of Axons. Raven, New York, 1978, pg 65.

25. Kelly WR, Blakemore WF, Jagelman $\mathrm{S}$, Webb HE - Demyelination induced in mice by avirulent Semliki Forest Virus: II. An ultrastructural study of focal demyelination in the brain. Neuropathol Appl Neurobiol 8:43, 1982. 
26. Kusaka H, Hirano A, Bornstein MB, Raine CS - Fine structure of astrocyte processes during serum-induced demyelination in vitro. J Neurol Sci 69:255, 1985.

27. Lampert $\mathbf{P W} \rightarrow$ Autoimmune and virus-induced demyelinating diseases: a review. Am $J$ Pathol 91:176, 1978.

28. Lampert PW - Fine structure of the demyelinating process. In Hallpike JF, Adams CWM, Tourtellotte WW (eds): Multiple Sclerosis: Pathology, Diagnosis and Management. Chapman, London, 1983, pg 29.

29. Lampert PW, Carpenter $\mathbf{S}$ - Electron microscopic studies on the vascular permeability and the mechanism of cemyelination in experimental allergic encephalomyelitis. $J$ Neuropathol Exp Neurol 24:11, 1965.

30. Leibowitz S, Hughes RAC - Immunology of the Nervous Systen. Edward Arnold, London, 1983.

31. Ludwin SK - Central nervous system demyelination and remyelination in the mouse: an ultrastructural study of cuprizone toxicity. Lab Invest 39:597, 1978.

32. Ludwin SK - Chronic demyelination inhibits remyelination in the central nervous system: an analysis of contributing factors. Lab Invest 43:382, 1980.

33. Mirsky R, Winter J, Abney ER, Pruss RM, Gavrilovic J, Raff MC - Myelin-specific proteins and glycolipids in rat Schwann cells and oligodendrocytes in culture. J Cell Biol 84:483, 1980.

34. McDonald WI - Remyelination in relation to clinical lesions in the central nervous system. $\mathrm{Br}$ Med BuIl 30:186, 1974.

35. Nagashima $\mathbf{K} \rightarrow$ Ultrastructural study of myelinating cells and sub-pial astrocytes in developing rat spinal cord. J Neurol Sci 44:1, 1979.

36. Peters A, Palay SL, Webster H deF - The Fine Structure of the Nervous System: the Neurons and Supporting Glia. WB Saunders, Philadelphia, 1976.

37. Powell HC, Lampert PW - Oligodendrocytes and their myelin-plasma membrane connections in JHM mouse hepatitis virus encephalomyelitis. Lab Invest 33:440, 1975.

38. Prineas JW, Raine CS - Mechanism of myelin breakdown in multiple sclerosis. J Neuropathol Exp Neurol 38:336, 1979.

39. Raine CS - Morphology of myelin and myelination. In Morell P (ed): Myelin. Ed 2. Plenum, New York, 1984, pg 1.

40. Raine CS, Hummelgard A, Swanson E, Bornstein MB - Multiple sclerosis: serum-induced demyelination in vitro. A light and electron microscopic study. I Neurol Sci 20:127, 1973.

41. Töro I, Ruzsa F, Röhlich $P$ - Ultrastructure of early phagocytic stages in sinus endothelial and Kupffer cells of the liver. Exp Cell Res 26:601, 1962.

42. Vandevelde M, Zurbriggen A, Higgins RJ, Palmer D - Spread and distribution of viral antigen in nervous system canine distemper. Acta Neuropathol (Berlin) 67:211, 1985.

43. Waxman SG - Conduction in normal and demyelinated axons. In Pearlman AL, Collins RC (eds): Neurological Pathophysiology. Oxford Univ Press, 1984, pg 13.

44. Weller RO - Experimental demyelinating diseases and their relevance to the study of multiple sclerosis. In Matthew WB (ed): McAlpine's Multiple Sclerosis. Churchill Livingstone, Edinburgh, 1985, pg 344.

45. Whitaker JN - Demyelinating diseases. In Pearlman AL, Collins RC (eds): Neurological Pathophysiology. Oxford Univ Press, 1984, pg 274.

46. Wisniewski H, Raine CS - An ultrastructural study of experimental demyelination and remyelination: V. Central and peripheral nervous system lesions caused by diphtheria toxin. Lab Invest $25: 73,1971$.

47. Wisniewski H, Bloom BR - Primary demyelination as a non-specific consequence of a cell-mediated immune reaction. J Exp Med 141:346, 1975.

48. Wisniewski H, Raine CS, Kay WJ - Observations on viral demyelinating encephalomyelitis: canine distemper. Lab Invest 26:589, 1972. 